\title{
Autism Speaks
}

\section{Author Manuscript}

Accepted for publication in a peer-reviewed journal

Published in final edited form as:

J Autism Dev Disord. 2015 December ; 45(12): 4015-4025. doi:10.1007/s10803-013-2016-3.

\section{Maternal Infection during Pregnancy and Autism Spectrum Disorders}

\author{
Ousseny Zerbo, $\mathrm{PhD}^{1}$, Yinge Qian, $\mathrm{MS}^{1}$, Cathleen Yoshida, $\mathrm{MA}^{1}$, Judith K. Grether, $\mathrm{PhD}^{2}$, \\ Judy Van de Water, $\mathbf{P h D}^{3}$, and Lisa A. Croen, $\mathrm{PhD}^{1}$ \\ ${ }^{1}$ Division of Research, Kaiser Permanente Northern California, Oakland, California 94612 \\ ${ }^{2}$ Retired, formerly with Environmental Health Investigations Branch, California Department of \\ Public Health, Richmond, California 94804 \\ ${ }^{3}$ Division of Rheumatology, Allergy and Clinical Immunology, University of California at Davis, \\ The M.I.N.D. Institute, University of California at Davis, and The NIEHS Center for Children's \\ Environmental Health, University of California, Davis, Davis, CA 95616, USA
}

\begin{abstract}
We conducted a nested case-control study including 407 cases and 2075 frequency matched controls to investigate the association between maternal infections during pregnancy and risk of autism spectrum disorders (ASD). Cases, controls, and maternal infections were ascertained from Kaiser Permanente Northern California clinical databases. No overall association between diagnoses of any maternal infection during pregnancy and ASD (adjusted odds ratio [ORadj] = $1.15,95 \%$ confidence interval $[\mathrm{CI}] 0.92-1.43$ ). However, women with infections diagnosed during a hospital admission (ORadj=1.48, 95\% CI1.07 - 2.04), particularly bacterial infections $(\mathrm{ORadj}=1.58,95 \%$ CI $1.06-2.37)$, were at increased risk of delivering a child with ASD. Multiple infections during pregnancy were associated with ASD $(\mathrm{ORadj}=1.36,95 \%$ CI $1.05-$ 1.78).
\end{abstract}

\section{Keywords}

Maternal infection; Pregnancy; Autism Spectrum Disorder

\begin{abstract}
Autism spectrum disorders (ASD) are a group of behaviorally-defined neurodevelopmental disorders characterized by impairments in social interaction and communication in combination with stereotyped or restricted behaviors and interests. Although not typically diagnosed until after the second year of life, evidence from neuropathology studies indicates that the biological processes leading to ASD begins during fetal development.(Arndt et al., 2005) While genetic susceptibility undoubtedly underlies autism etiology in many cases
\end{abstract}

Corresponding author: Ousseny Zerbo, PhD, Division of Research, Kaiser Permanente, 2000 Broadway, Oakland, CA 94612. Tel: (510) 891-3524, Fax: (510) 891-5976. Ousseny.x.zerbo@kp.org.

CONFLICT OF INTEREST

The authors declare that they have no conflict of interest.

The findings and conclusions in this report are those of the authors and do not necessarily represent the views of the Centers for Disease Control and Prevention. 
(Abrahams and Geschwind, 2008), non-genetic factors likely play a role as well (Hallmayer et al., 2011) and may contribute to the increase in diagnosed ASD that has been widely reported during the past two decades.(Croen et al., 2002; Hertz-Picciotto and Delwiche, 2009)

Previous epidemiological studies indicate that prenatal exposure to viral infections is a possible pathway through which autism spectrum disorders (ASD) could be initiated in some children. Cases of autism following congenital cytomegalovirus, perinatal herpes simplex virus, and congenital rubella infections have been reported.(Chess, 1971; Deykin and MacMahon, 1979; Ghaziuddin et al., 1992; Yamashita et al., 2003) Gestational exposure to measles, rubella, and mumps and postnatal exposure to mumps and varicella were associated with higher autism risk in a large epidemiologic study.(Mason-Brothers et al., 1990) Recently, maternal fever during pregnancy has been linked to increased risk of ASD. (Zerbo et al., 2012) Animal model studies have also shown that autistic-like behaviors can be induced by maternal infectious exposure during gestation (Shi et al., 2003) and, in the absence of viral antigens, by stimulation during gestation of the maternal immune response. (Hsiao and Patterson, 2012; Malkova et al., 2012; Shi et al., 2009) Maternal antibodies raised in response to viruses or bacteria may cross the placenta and disrupt fetal neurodevelopment by cross-reacting with fetal brain antigens via molecular mimicry. (Braunschweig and Van de Water, 2012; Shi, et al., 2003) In mice, autistic-like brain structure and behavioral patterns were induced in the offspring of dams injected during pregnancy with serum antibodies obtained from a mother of children with autism.(Dalton et al., 2003) However, in humans, higher levels of immunoglobulins in newborn blood was associated with lower risk for autism, a finding which may be inconsistent with the hypothesis that maternal infection is a risk factor for autism. (Grether et al., 2010) Therefore, additional human studies are needed to clarify the possible association between maternal infections or markers of infections and risk of autism.

We conducted a case-control study to investigate the potential association between maternal infection during pregnancy and risk of delivering an infant subsequently diagnosed with an ASD.

\section{Methods}

\section{Study Population}

Our study population was drawn from the Childhood Autism Perinatal Study (CHAPS), a large case-control study examining pre-, peri-, and neonatal risk factors for ASDs among the membership of Kaiser Permanente of Northern California (KPNC).(Croen et al., 2005) $\mathrm{KPNC}$ is a group model, integrated health plan that provides care for over 3.2 million northern California residents. The KPNC membership represents approximately $30 \%$ of the insured population in the region and is demographically similar to the residents of the counties served by KPNC, except that the very poor and very wealthy are underrepresented. (Krieger, 1992) Cases and controls were identified from the cohort of infants born at a KPNC facility between January 1995 and June 1999 who remained KPNC members for at least 2 years following birth. Cases $(n=420)$ were defined as children with at least one diagnosis of an ASD, including autism (International Classification of Diseases, 9th 
Revision, Clinical Modification [ICD-9-CM] code 299.0) and Asperger disorder or Pervasive Developmental Disorder Not Otherwise Specified (PDD_NOS) (ICD-9-CM code 299.8) recorded anytime between January 1995 and December 2002.

ASD diagnoses were identified by electronically scanning the KPNC outpatient clinical databases, which contain all diagnoses made at outpatient visits occurring at plan facilities and outside approved facilities. Five controls per case $(n=2,100)$ were randomly selected from the cohort of KPNC births without an ASD diagnosis, frequency matched to cases on sex, birth year, and delivery hospital.

To insure independence of observations with respect to characteristics of the mother, we sampled one child from each woman for inclusion in the final analytic file as follows: if a woman had one child with autism and the other without autism, we selected the child with autism $(n=13)$; if two control children, we randomly selected one $(n=5)$. None of the 13 case mothers had two children with autism. In addition, we excluded 20 children originally sampled as controls and who were subsequently diagnosed with an ASD. The final analytic sample consisted of 407 cases and 2,075 controls.

\section{Maternal Infections}

The type and timing of maternal infections during pregnancy were ascertained from KPNC databases, which prospectively capture all diagnoses made during inpatient hospitalizations and outpatient clinic visits within KPNC and approved outside facilities. All infections diagnosed from 30 days prior to conception through the date of delivery were included.

Infections, defined by ICD-9-CM codes, were grouped according to two broad categories: organism-specific infections (viral, bacterial, mycosal, parasitic, unknown) and organspecific infections (cardiovascular, ear, eye, gastrointestinal, genitourinary, lower respiratory, upper respiratory, skin, other, unknown). Each ICD-9-CM code was assigned to one organism and one organ category. Infections for which the type of organism or affected organ could not be determined with certainty were assigned to the unknown category. Specific ICD-9-CM codes included in each category are displayed in Table 1. We also determined the total number of maternal infections diagnosed during pregnancy and total number within each infection category and time period of exposure. Infections in the same category diagnosed less than 30 days apart were considered the same infection and counted only once.

Four time periods of exposure were defined: preconception (the 30 days prior to the last menstrual period (LMP)), first trimester (90 days post-LMP), second trimester (90 - 179 days post-LMP), and third trimester (180 days post-LMP to date of delivery). "Any time during pregnancy" was defined as the time between the LMP and the date of delivery, and excluded the preconception period. To account for possible inaccuracies in LMP date, and to capture infections diagnosed prior to conception that may have still been active after conception, the preconception period was included as a proxy for very early pregnancy exposure. Infections in the same category diagnosed in separate time periods were counted in each time period, even if also occurring in a prior or later time period. Information on maternal exposure to anti-infective medications was ascertained from the KPNC pharmacy 
database, which records all dispensed prescriptions for KPNC members. All prescriptions in the 30 days before conception through the end of the pregnancy with the study child were identified. Medications were grouped according to the type of organism they were targeting (e.g., antibiotic, antiviral, antiparasitic, antifungal). Exposure to medication during a given time period was assumed if a prescription was dispensed during that time period.

\section{Covariates}

Information on several maternal characteristics (age at delivery, race/ethnicity, educational attainment at delivery, parity) and infant characteristics (sex, birth weight, gestational age, plurality [i.e., singleton or multiple]) was obtained from medical records and health plan and vital statistics databases.

\section{Statistical Analysis}

Characteristics of cases and controls were compared using contingency tables.

Unconditional logistic regression analysis was conducted to produce odds ratios as a measure of association between ASD and maternal infection during pregnancy. For each exposure definition (organism-specific, organ-specific), we examined associations by time period of exposure (anytime during pregnancy, preconception, 1st trimester, 2nd trimester, 3rd trimester). Logistic regression models were run for infections diagnosed during inpatient and outpatient visits combined, and separately for infections diagnosed during inpatient visits. We also conducted analyses stratified by medication use to treat infections. Women with no infections for the entire period from 30 days before LMP through the end of pregnancy were considered unexposed for all analyses. Maternal and infant characteristics associated with both case-control status and maternal infection during pregnancy were considered potential confounders and entered in multivariate models predicting ASD. We fitted a series of multivariate regression models to the data, initially including the main exposure and all potential confounders identified in the bivariate analysis. Covariates were retained in the model only if they changed the magnitude of the odds ratio of maternal infection by at least $10 \%$. All matching variables (gender, birth year, hospital of birth) were included in all multivariate analyses regardless of impact on the odds ratios. As preterm birth may be intermediary between maternal infection (Cram et al., 2002) and autism (PintoMartin et al., 2011), analyses were not stratified by gestational age. Stratifying on a variable that can be a marker for exposure would lead to biased results. (Hernan et al., 2002; Weinberg, 1993) Risk estimates were calculated only for infection categories for which at least 5 cases and 5 controls were exposed.

Study procedures were approved by the KPNC Institutional Review Board and the California State Committee for the Protection of Human Subjects.

\section{Results}

Children with autism spectrum disorder (ASD) were more likely than control children to be multiple births (twin or triplet), born at $<37$ weeks gestation and to have a mother who was older at delivery, had a higher level of education, and was white, non-Hispanic (Table 2). Among controls, mothers with any infection during pregnancy were more likely than those 
without diagnosed infections to be younger and be white, non-Hispanic or black. In all reported measures of association (odds ratios), we adjusted for maternal age and race/ ethnicity, in addition to the matching variables (child sex, birth hospital and birth year). Maternal education and plurality did not affect the measure of association between ASD and maternal infection in multivariable analyses, and therefore were not included in the final adjusted models.

\section{All infections combined}

Nearly $50 \%$ of both case and control mothers had at least one infection diagnosed as an outpatient or inpatient at any time during pregnancy. The frequency of maternal infection anytime during the pregnancy period, for the preconception period, and for each trimester was similar for cases and controls (Table 3).

\section{Organ-specific infections}

Genitourinary (GU) infections were among the more commonly diagnosed infections during pregnancy among both case and control mothers (Table 4). During the entire pregnancy period and during the 2nd and 3rd trimesters, GU infections were diagnosed somewhat more often in case than control mothers but risk estimates were of borderline significance (Table 4). The most frequently diagnosed GU infections during pregnancy were Candida Vulvovaginitis (ICD-9-CM 112.1), Urinary Tract Infection Not Otherwise Specified (NOS) (ICD-9-CM 599.0) and Vaginitis NOS (ICD-9-CM 616.10).

Skin infections diagnosed in the preconception period and infections of unknown organ system diagnosed anytime during pregnancy and the 2nd trimester were also more common in case mothers compared with controls (Table 4).

\section{Organism-specific infections}

Maternal bacterial infections during pregnancy, during the second trimester and the third trimester were associated with moderately increased ASD risk ( $<2$-fold) of borderline statistical significance (Table 5). The vast majority of bacterial infections occurred during the third trimester. The most common bacterial infections during this period were Urinary Tract Infection NOS (ICD-9-CM 599.0), Amniotic Infection at Delivery (ICD-9-CM 658.41), and Major Puerperal Infection (ICD-9-CM 670.02).

Mothers of children with ASD were diagnosed with viral infections no more often than mothers of control children at any time during pregnancy, or during any trimester (Table 5). There were no diagnoses of cytomegalovirus or measles in this study population, and other specific viral infections previously reported to be associated with risk of ASD were diagnosed infrequently (Herpes Simples: 3 cases, 21 controls; Influenza: 3 cases, 19 controls; Rubella: 0 cases, 1 control; Varicella: 0 cases, 4 controls).

Mycosal infections during pregnancy were marginally associated with increased risk of ASD (Table 5). Parasitic infections were rare and only observed in control mothers. 


\section{Infections diagnosed during hospitalizations}

Case mothers were about 50\% more likely than control mothers to have an infection diagnosed during a hospital admission at some point during pregnancy (Table 6). Most inpatient infections occurred in the third trimester and were diagnosed on the day of delivery (49/59 among cases, 214/242 among controls). Although not very common, inpatient infections diagnosed during the second trimester were associated with the highest risk of ASD (Table 6). Bacterial infections accounted for the majority of infections diagnosed during a hospital admission, and were associated with increased risk of ASD (Table 6). The majority of bacterial infections were diagnosed in the third trimester. Genitourinary infections (50\% cases vs. $44 \%$ controls), urinary tract infections ( $23 \%$ cases vs. $14 \%$ controls) and amniotic fluid infections at delivery ( $40 \%$ cases vs. $51 \%$ controls) were the most commonly-diagnosed bacterial infections. A very small percentage of bacterial infections in the third trimester were diagnosed as bacterial vaginosis (1/35 mothers of cases and 6/144 mothers of controls).

\section{Numbers of infections}

Mothers of ASD children were more likely than mothers of controls to have two or more infections during pregnancy $(34.5 \%$ vs. $29.1 \%$ ORadj $=1.36,95 \%$ CI $1.05-1.78)$. Two or more infections diagnosed in the third trimester of pregnancy was associated with even higher increased risk of ASD (16.5\% vs. $10.6 \%$ ORadj $=1.76,95 \%$ CI $1.25-2.48)$

\section{Treatment}

Treatment of infection in an outpatient setting did not change the association between maternal infection during pregnancy and risk of ASD. ASD risk was statistically similar for mothers who treated their infection (94 cases and 444 controls, ORadj $=1.14,95 \%$ CI $0.86-$ 1.50) and for mothers who did not treat their infection (104 cases and 516 controls, ORadj = $1.13,95 \%$ CI $0.86-1.47)$.

\section{Discussion}

In our study population, about $50 \%$ of women had a documented infection during pregnancy. This proportion is similar to the $64 \%$ reported earlier by Collier et al. (2009). We did not find an overall association between diagnoses of any maternal infection during pregnancy and ASD in the child. However, women with any infections diagnosed during a hospital admission, particularly bacterial infections, were at increased risk of delivering a child who was diagnosed with ASD. The most commonly- diagnosed bacterial infections in our study were urinary tract infections. A previous study that found an association between bacterial infection diagnosed during a hospitalization and ASD also reported urinary tract infections as the most common bacterial infection.(Atladottir et al., 2010) Infections diagnosed in the inpatient setting are likely more severe than those diagnosed in the outpatient setting. Our findings that mothers with 2 or more diagnosed infections were at higher risk of having a child with autism also supports the suggestion that more severe infections during pregnancy may increase the risk of ASD. In the present study, the proportion of women with infection diagnosed during a hospitalization (16\% of case mothers and $12 \%$ of control mothers) is much higher than that reported by two previous 
Danish studies which reported respectively only 1.3\% (Atladottir, et al., 2010) and 2\%. (Abdallah et al., 2011)

We did not observe an association between maternal viral infections during pregnancy and ASD risk. This is in contrast to previous case reports and small studies indicating that rubella, cytomegalovirus, and influenza increased risk of ASD. (Chess, 1971; Deykin and MacMahon, 1979; Yamashita, et al., 2003) There were no diagnoses of cytomegalovirus and rubella infections documented in medical records in our study population. Our results are also inconsistent with those of two recent Danish studies. The first reported an association between maternal viral infection in the first trimester and ASD in the offspring (Atladottir, et al., 2010) and the second found an increased risk of infantile autism associated with maternal influenza infection during pregnancy.(Atladottir et al., 2012) Although both studies included large sample sizes, the results of the second study were based on self-reported influenza infection collected from women shortly after they became pregnant rather than physician-documented diagnoses. Self-reported data on infection may suffer from overcounting or under-counting, depending on severity and characteristics of the mothers related to access to health care and care-seeking behavior. It is also possible that medical records may undercount viral infections, since physicians discourage seeking their services for viruses.

Women who had an infection 30 days before conception had a non-statistically elevated risk of having a child diagnosed with autism. This suggests that maternal immune activation around the time of conception may adversely impact fetal neurodevelopment

Our study had several strengths, including large numbers of subjects, population-based identification of cases and controls from the same birth cohort, the use of prospectivelycollected information on diagnoses documented in medical records, and an appropriately matched internal comparison group with no documented ASD diagnoses. We were also able to examine the risk for specific periods during pregnancy and to adjust for several important covariates.

Despite these strengths, our findings must be considered in the context of several study limitations. ASD status was determined by diagnoses recorded in medical records, and not validated by a standardized clinical assessment for all cases. However, in a subset of 50 children evaluated with the Autism Diagnostic Interview-Revised (ADI-R) (Lord et al., 1994) and the Autism Diagnostic Observation Schedule-Generic (ADOS-G) (Lord et al., 2000), $94 \%$ met criteria for ASD on both instruments, and $100 \%$ met criteria on at least one instrument. (Croen et al., 2008) In addition, record-review validation studies conducted by the investigators have demonstrated that at least $90 \%$ of children with an ASD diagnosis recorded in the KPNC electronic databases have documentation consistent with a diagnosis of autism based on DSM-IV criteria.(Croen, et al., 2008) We were unable to evaluate phenotypic subgroups of cases, based on severity of ASD or other characteristics, such as presence of intellectual disability as the data in medical records were not sufficient to accurately and completely make these distinctions. 
Infections included in our study were restricted to those documented in medical records, and based on ICD9 diagnostic codes, rather than serologic evidence. Subclinical infections or illnesses for which women did not seek medical attention were not counted. Information on treatment was limited to prescription medications picked up at a KPNC pharmacy, and may not accurately reflect actual exposure to all medication use during pregnancy. Our analysis may have missed over-the-counter medications such as fever reducers or anti-inflammatory drugs, and undercounted medication given to women during their hospitalization. We did not have information on possible confounding factors, such as alcohol intake or vitamin supplementation. Our analysis was also hampered by small numbers in some cells, which is reflected in the wide confidence intervals around some of the point estimates. Moreover, because of the relatively small sample size, we had limited power to distinguish the effect of treatment from that of infection on risk of ASD. Finally, because we were interested in identifying all possible associations, we did not correct the results for multiple comparisons. Due to the number of analyses we conducted, our findings could be due to chance, and require follow-up in larger studies.

The mechanism by which maternal infection during pregnancy might lead to neurodevelopmental disorders such as autism is unclear. Previous studies have suggested both direct effects via the passage of infectious organisms across the placenta and entering the fetal environment (Aronsson et al., 2002) or indirect effects via maternal immune activation.(Hsiao et al., 2012; Malkova, et al., 2012; Patterson, 2011) Activation of the maternal immune system by viral or bacterial mimics (Ashdown et al., 2006) in the absence of the actual organisms is sufficient to induce abnormal brain structure and behavior in animal offspring.(Shi, et al., 2009; Short et al., 2010; Soumiya et al., 2011) Cytokines and chemokines play a role in neurodevelopment including neuronal migration and synaptic plasticity during development.(Bauer et al., 2007; Rostene et al., 2007) However, in some instances they can be detrimental to the developing fetus. In animal models, injection of the cytokine interleukin (IL) 6 into pregnant mice led to the development of neurodevelopment abnormalities in the offspring. Animal model studies have suggested that the association between maternal influenza infection and neurodevelopmental disorders like autism may be mediated through IL-6.(Smith et al., 2007) However, such findings have not been replicated in human studies. It is not known how maternal immune activation (MIA) through elevated levels of maternal cytokines may lead to developmental abnormalities like autism. Three possible pathways have been proposed: a) cytokines of maternal origin cross the placenta and act on the fetal central nervous system leading to later neurodevelopmental disorders, b) MIA induces a placental inflammatory state leading to placental cytokine secretion which can pass to the fetus and lead to autism, or c) MIA can trigger a fetal inflammatory response which has been reported in children with autism.(Jonakait, 2007; Parker-Athill and Tan, 2010) A recent animal model experiment suggested that maternal immune activation during pregnancy leads to permanently altered peripheral immune cells in the offspring.(Hsiao, et al., 2012) It is possible that a combination of all three pathways, upon reaching a threshold response, converge to affect the developmental trajectory. However, future studies will be needed to evaluate this hypothesis.

Another potential mechanism by which maternal infection could increase risk of ASD is via pregnancy and delivery complications. (Reviewed in Guinchat et al., 2012) There is strong 
evidence that maternal infection during pregnancy is associated with preterm delivery (Cram et al., 2002), and evidence that preterm delivery is associated with autism risk. (Pinto-Martin et al., 2011) Cytokines such as TNF-a or IL-6 produced in response to intrauterine infections have been suggested to contribute to both preterm birth and periventricular white matter damage. (Dammann and O'Shea, 2008) In some cases of autism, abnormal white matter has been reported. (Cheng et al., 2010)

Previously, we found that elevated levels of the cytokines interferon $\gamma$ (IFN- $\gamma$ ), IL-4 and IL-5 in mid- pregnancy serum was associated with increased risk of ASD in children. (Goines et al., 2011) A recent study also reported an association between amniotic fluid cytokines (IL-4, IL-10, TNF- $\alpha$ and TNF- $\beta$ ), chemokines (MCP-1) and autism.(Abdallah, et al., 2011; Abdallah et al., 2012) More studies are needed to elucidate the biologic mechanisms underlying the associations between maternal infection, preterm delivery, and autism.

\section{Conclusion}

Multiple maternal infections and bacterial infections occurring during late pregnancy, particularly those diagnosed in a hospital setting, were associated with a higher risk of autism. Future studies designed to overcome the limitations of this study and tease apart the underlying biologic mechanisms leading to this observation are warranted.

\section{Acknowledgments}

The authors would like to thank Dr. Kath Dorward, MD, from the department of Obstetrics and Gynecology at Kaiser Permanente San Francisco for her input on maternal infections during pregnancy.

FUNDING:

This study was funded by grants from the Centers for Disease Control and Prevention, (U10/CCU920392), the Kaiser Foundation Research Institute, and Autism Speaks.

\section{References}

Abdallah MW, Larsen N, Grove J, Norgaard-Pedersen B, Thorsen P, Mortensen EL, et al. Amniotic fluid inflammatory cytokines: Potential markers of immunologic dysfunction in autism spectrum disorders. World J Biol Psychiatry. 2011

Abdallah MW, Larsen N, Grove J, Norgaard-Pedersen B, Thorsen P, Mortensen EL, et al. Amniotic fluid chemokines and autism spectrum disorders: an exploratory study utilizing a Danish Historic Birth Cohort. Brain Behav Immun. 2012; 26(1):170-176. [PubMed: 21933705]

Abrahams BS, Geschwind DH. Advances in autism genetics: on the threshold of a new neurobiology. Nat Rev Genet. 2008; 9(5):341-355. [PubMed: 18414403]

Arndt TL, Stodgell CJ, Rodier PM. The teratology of autism. Int J Dev Neurosci. 2005; 23(2-3):189199. [PubMed: 15749245]

Aronsson F, Lannebo C, Paucar M, Brask J, Kristensson K, Karlsson H. Persistence of viral RNA in the brain of offspring to mice infected with influenza A/WSN/33 virus during pregnancy. $\mathrm{J}$ Neurovirol. 2002; 8(4):353-357. [PubMed: 12161820]

Ashdown H, Dumont Y, Ng M, Poole S, Boksa P, Luheshi GN. The role of cytokines in mediating effects of prenatal infection on the fetus: implications for schizophrenia. Mol Psychiatry. 2006; 11(1):47-55. [PubMed: 16189509]

Atladottir HO, Henriksen TB, Schendel DE, Parner ET. Autism After Infection, Febrile Episodes, and Antibiotic Use During Pregnancy: An Exploratory Study. Pediatrics. 2012 
Atladottir HO, Thorsen P, Ostergaard L, Schendel DE, Lemcke S, Abdallah M, et al. Maternal infection requiring hospitalization during pregnancy and autism spectrum disorders. J Autism Dev Disord. 2010; 40(12):1423-1430. [PubMed: 20414802]

Bauer S, Kerr BJ, Patterson PH. The neuropoietic cytokine family in development, plasticity, disease and injury. Nat Rev Neurosci. 2007; 8(3):221-232. [PubMed: 17311007]

Braunschweig D, Van de Water J. Maternal autoantibodies in autism. Arch Neurol. 2012; 69(6):693699. [PubMed: 22689191]

Cheng Y, Chou KH, Chen IY, Fan YT, Decety J, Lin CP. Atypical development of white matter microstructure in adolescents with autism spectrum disorders. Neuroimage. 2010; 50(3):873-882. [PubMed: 20074650]

Chess S. Autism in children with congenital rubella. J Autism Child Schizophr. 1971; 1(1):33-47. [PubMed: 5172438]

Collier SA, Rasmussen SA, Feldkamp ML, Honein MA. Prevalence of self-reported infection during pregnancy among control mothers in the National Birth Defects Prevention Study. Birth Defects Res A Clin Mol Teratol. 2009; 85(3):193-201. [PubMed: 19086018]

Cram LF, Zapata MI, Toy EC, Baker B 3rd. Genitourinary infections and their association with preterm labor. Am Fam Physician. 2002; 65(2):241-248. [PubMed: 11820488]

Croen LA, Grether JK, Hoogstrate J, Selvin S. The changing prevalence of autism in California. J Autism Dev Disord. 2002; 32(3):207-215. [PubMed: 12108622]

Croen LA, Grether JK, Yoshida CK, Odouli R, Van de Water J. Maternal autoimmune diseases, asthma and allergies, and childhood autism spectrum disorders: a case-control study. Arch Pediatr Adolesc Med. 2005; 159(2):151-157. [PubMed: 15699309]

Croen LA, Matevia M, Yoshida CK, Grether JK. Maternal Rh D status, anti-D immune globulin exposure during pregnancy, and risk of autism spectrum disorders. Am J Obstet Gynecol. 2008; 199(3):234, e231-236. [PubMed: 18554566]

Dalton P, Deacon R, Blamire A, Pike M, McKinlay I, Stein J, et al. Maternal neuronal antibodies associated with autism and a language disorder. Ann Neurol. 2003; 53(4):533-537. [PubMed: 12666123]

Dammann O, O'Shea TM. Cytokines and perinatal brain damage. Clin Perinatol. 2008; 35(4):643663. v. [PubMed: 19026332]

Deykin EY, MacMahon B. Viral exposure and autism. Am J Epidemiol. 1979; 109(6):628-638. [PubMed: 222139]

Ghaziuddin M, Tsai LY, Eilers L, Ghaziuddin N. Brief report: autism and herpes simplex encephalitis. J Autism Dev Disord. 1992; 22(1):107-113. [PubMed: 1592760]

Goines PE, Croen LA, Braunschweig D, Yoshida CK, Grether J, Hansen R, et al. Increased midgestational IFN-gamma, IL-4, and IL-5 in women giving birth to a child with autism: a casecontrol study. Mol Autism. 2011; 2(1):13. [PubMed: 21810230]

Grether JK, Croen LA, Anderson MC, Nelson KB, Yolken RH. Neonatally measured immunoglobulins and risk of autism. Autism Res. 2010; 3(6):323-332. [PubMed: 21182209]

Guinchat V, Thorsen P, Laurent C, Cans C, Bodeau N, Cohen D. Pre-, peri- and neonatal risk factors for autism. Acta Obstet Gynecol Scand. 2012; 91(3):287-300. [PubMed: 22085436]

Hallmayer J, Cleveland S, Torres A, Phillips J, Cohen B, Torigoe T, et al. Genetic Heritability and Shared Environmental Factors Among Twin Pairs With Autism. Arch Gen Psychiatry. 2011

Hernan MA, Hernandez-Diaz S, Werler MM, Mitchell AA. Causal knowledge as a prerequisite for confounding evaluation: an application to birth defects epidemiology. Am J Epidemiol. 2002; 155(2):176-184. [PubMed: 11790682]

Hertz-Picciotto I, Delwiche L. The rise in autism and the role of age at diagnosis. Epidemiology. 2009; 20(1):84-90. [PubMed: 19234401]

Hsiao EY, McBride SW, Chow J, Mazmanian SK, Patterson PH. Modeling an autism risk factor in mice leads to permanent immune dysregulation. Proc Natl Acad Sci U S A. 2012; 109(31):1277612781. [PubMed: 22802640]

Hsiao EY, Patterson PH. Placental regulation of maternal-fetal interactions and brain development. Dev Neurobiol. 2012 
Jonakait GM. The effects of maternal inflammation on neuronal development: possible mechanisms. Int J Dev Neurosci. 2007; 25(7):415-425. [PubMed: 17949937]

Krieger N. Overcoming the absence of socioeconomic data in medical records: validation and application of a census-based methodology. Am J Public Health. 1992; 82(5):703-710. [PubMed: 1566949]

Lord C, Risi S, Lambrecht L, Cook EH Jr, Leventhal BL, DiLavore PC, et al. The autism diagnostic observation schedule-generic: a standard measure of social and communication deficits associated with the spectrum of autism. J Autism Dev Disord. 2000; 30(3):205-223. [PubMed: 11055457]

Lord C, Rutter M, Le Couteur A. Autism Diagnostic Interview-Revised: a revised version of a diagnostic interview for caregivers of individuals with possible pervasive developmental disorders. J Autism Dev Disord. 1994; 24(5):659-685. [PubMed: 7814313]

Malkova NV, Yu CZ, Hsiao EY, Moore MJ, Patterson PH. Maternal immune activation yields offspring displaying mouse versions of the three core symptoms of autism. Brain Behav Immun. 2012; 26(4):607-616. [PubMed: 22310922]

Mason-Brothers A, Ritvo ER, Pingree C, Petersen PB, Jenson WR, McMahon WM, et al. The UCLAUniversity of Utah epidemiologic survey of autism: prenatal, perinatal, and postnatal factors. Pediatrics. 1990; 86(4):514-519. [PubMed: 2216614]

Parker-Athill EC, Tan J. Maternal immune activation and autism spectrum disorder: interleukin-6 signaling as a key mechanistic pathway. Neurosignals. 2010; 18(2):113-128. [PubMed: 20924155]

Patterson PH. Maternal infection and immune involvement in autism. Trends Mol Med. 2011

Pinto-Martin JA, Levy SE, Feldman JF, Lorenz JM, Paneth N, Whitaker AH. Prevalence of autism spectrum disorder in adolescents born weighing <2000 grams. Pediatrics. 2011; 128(5):883-891. [PubMed: 22007018]

Rostene W, Kitabgi P, Parsadaniantz SM. Chemokines: a new class of neuromodulator? Nat Rev Neurosci. 2007; 8(11):895-903. [PubMed: 17948033]

Shi L, Fatemi SH, Sidwell RW, Patterson PH. Maternal influenza infection causes marked behavioral and pharmacological changes in the offspring. J Neurosci. 2003; 23(1):297-302. [PubMed: 12514227]

Shi L, Smith SE, Malkova N, Tse D, Su Y, Patterson PH. Activation of the maternal immune system alters cerebellar development in the offspring. Brain Behav Immun. 2009; 23(1):116-123. [PubMed: 18755264]

Short SJ, Lubach GR, Karasin AI, Olsen CW, Styner M, Knickmeyer RC, et al. Maternal influenza infection during pregnancy impacts postnatal brain development in the rhesus monkey. Biol Psychiatry. 2010; 67(10):965-973. [PubMed: 20079486]

Smith SE, Li J, Garbett K, Mirnics K, Patterson PH. Maternal immune activation alters fetal brain development through interleukin-6. J Neurosci. 2007; 27(40):10695-10702. [PubMed: 17913903]

Soumiya H, Fukumitsu H, Furukawa S. Prenatal immune challenge compromises the normal course of neurogenesis during development of the mouse cerebral cortex. J Neurosci Res. 2011; 89(10): 1575-1585. [PubMed: 21732402]

Weinberg CR. Toward a clearer definition of confounding. Am J Epidemiol. 1993; 137(1):1-8. [PubMed: 8434568]

Yamashita Y, Fujimoto C, Nakajima E, Isagai T, Matsuishi T. Possible association between congenital cytomegalovirus infection and autistic disorder. J Autism Dev Disord. 2003; 33(4):455-459. [PubMed: 12959425]

Zerbo O, Iosif AM, Walker C, Ozonoff S, Hansen RL, Hertz-Picciotto I. Is Maternal Influenza or Fever During Pregnancy Associated with Autism or Developmental Delays? Results from the CHARGE (CHildhood Autism Risks from Genetics and Environment) Study. J Autism Dev Disord. 2012 


\section{Table 1}

List of ICD-9-CM Codes Included in Each Infection Category, Childhood Autism Perinatal Study, 1995 1999

\begin{tabular}{|c|c|}
\hline Infection Categories & ICD-9 Codes \\
\hline \multicolumn{2}{|c|}{ Organism-specific Infection Categories } \\
\hline Bacterial infections & $\begin{array}{l}001-005,008.0-008.5,010-018,020-027,030-041,079.9,079.98,080-083,088.0,090-098, \\
320-322,373.11,424,461,481,482,483,537.9,540,542,567,574.00,575.1,590,595,597, \\
599.0,614,616,646.5,647.0,647.1,647.3,658.4,659.31,670.02,681,682,684,686,795.5 \\
919.5\end{array}$ \\
\hline Mycoses & $110-118$ \\
\hline Parasitic infections & 006, 007, 084-087, 088.8, 120-129, 130-136, 647.4, 647.8 \\
\hline Viral infections & $\begin{array}{l}\text { 008.6, 008.8, 042, 045-049, 050-057, 060-066, 070-077, 079.0-079.89, 079.99, 460, 466, 480, } \\
487,571.4,573.1-573.3,647.5,647.6\end{array}$ \\
\hline Unknown organism & $\begin{array}{l}099.9,350.2,351.0,370.20,371.00,372.00,372.3,372.30,373.00,380.10,380.23,381.3,381.4, \\
382.9,462,463,464.0,465.9,466.0,472.0,473.9,486,490,491.9,528.0,530.1,530.10,533.90, \\
535.0,535.00,535.50,575.8,575.9,597.80,599.7,616.0,616.10,646.61-646.63,647.23,647.81, \\
647.83,647.91,686.9,730.90\end{array}$ \\
\hline \multicolumn{2}{|c|}{ Organ-specific Infection Categories } \\
\hline Cardiovascular & $421,422.0,424$ \\
\hline Skin & 035, 053, 078.0, 078.1, 110, 111, 117.1, 117.2, 133, 680-682, 684--686, \\
\hline Ear & $380-382$ \\
\hline Eye & $054.4,076,370-373$ \\
\hline Gastrointestinal & $\begin{array}{l}001-009,040.2,041.4,070,072112.0,123.0,123.2-123.9,528.0,528.1,528.3,530.1,530.2 \\
531.9,531-533,535,537.9,540,542,570-573,574.00,575.0,575.1,575.8,575.9,577.0,577.1\end{array}$ \\
\hline Genitourinary & $\begin{array}{l}041.6,054,078.1,079.9,079.98,098.0-098.3,112.1,131.00-131.02,132.2,590,599,614,616 \text {, } \\
646\end{array}$ \\
\hline Lower Respiratory & 010-012, 115, 466,480-487, 490, 491, 795.5 \\
\hline Upper Respiratory & $032,033,040.1,041.5,460-465,472,473,476$ \\
\hline Unknown organ & $\begin{array}{l}\text { 038.0, 038.11, 047.9, 041.04, 041.10, 041.11, 041.19, 041.85, 041.89, 041.9, 052.9, 054.8, 054.9, } \\
079.89,079.99,097.1,099.9,112.9,134.9,350.2,351.0,567.2,647.01,647.23,647.61,647.63 \text {, } \\
647.51,647.81,647.83,647.91,658.41,659.31,670.02,730.90,919.5,998.5\end{array}$ \\
\hline
\end{tabular}


Table 2

Characteristics of Study Population, Kaiser Permanente Northern California Childhood Autism Perinatal Study, $1995-1999$

\begin{tabular}{|c|c|c|}
\hline & $\begin{array}{c}\text { Cases }(N=407) \\
n(\%)\end{array}$ & $\begin{array}{c}\text { Controls }(N=2075) \\
\text { n }(\%)\end{array}$ \\
\hline Female & $74(18.2)$ & $385(18.5)$ \\
\hline Male & $333(81.8)$ & $1690(81.4)$ \\
\hline \multicolumn{3}{|l|}{ Plurality } \\
\hline Singleton & $383(94.1)$ & $2010(96.8)$ \\
\hline Multiple (twin or triplet) & $24(5.9)$ & $57(2.7)$ \\
\hline \multicolumn{3}{|l|}{ Maternal Age (years) } \\
\hline$<20$ & $6(1.5)$ & $85(4.1)$ \\
\hline $20-24$ & $45(11.0)$ & $298(14.4)$ \\
\hline $25-29$ & $100(24.6)$ & $584(28.1)$ \\
\hline $30-34$ & $137(33.7)$ & $660(31.8)$ \\
\hline $35-39$ & $99(24.3)$ & $374(18.0)$ \\
\hline$\geq 40$ & $20(4.9)$ & $74(3.6)$ \\
\hline \multicolumn{3}{|l|}{ Maternal Education } \\
\hline$<$ High school & $21(5.2)$ & $206(9.9)$ \\
\hline High school graduate & $79(19.4)$ & $597(28.8)$ \\
\hline College & $223(54.8)$ & $983(47.4)$ \\
\hline Post-graduate & $81(19.9)$ & $256(12.3)$ \\
\hline Unknown & $3(0.7)$ & $25(1.2)$ \\
\hline \multicolumn{3}{|l|}{ Maternal Race/Ethnicity } \\
\hline White, non-Hispanic & $210(51.6)$ & $936(45.1)$ \\
\hline White, Hispanic & $66(16.2)$ & $471(22.7)$ \\
\hline Black & $35(8.6)$ & $186(8.9)$ \\
\hline Asian & $42(10.3)$ & $215(10.4)$ \\
\hline Other & $54(13.3)$ & $267(12.9)$ \\
\hline \multicolumn{3}{|l|}{ Gestational Age } \\
\hline < 37 Weeks & $42(10.3)$ & $134(6.5)$ \\
\hline 237 Weeks & $365(89.7)$ & $1941(93.5)$ \\
\hline \multicolumn{3}{|l|}{ Birth Weight } \\
\hline$<2500$ grams & $28(6.9)$ & $101(4.9)$ \\
\hline$\geq 2500$ grams & $379(93.1)$ & $1974(95.1)$ \\
\hline \multicolumn{3}{|l|}{ Parity } \\
\hline Primiparous & $172(42.3)$ & $891(42.9)$ \\
\hline Multiparous & $234(57.5)$ & $1176(56.7)$ \\
\hline Missing & $1(0.2)$ & $8(0.4)$ \\
\hline \multicolumn{3}{|l|}{ Birth Year } \\
\hline 1995 & $119(29.2)$ & $607(29.3)$ \\
\hline 1996 & $106(26.0)$ & $550(26.5)$ \\
\hline 1997 & $78(19.2)$ & $387(18.7)$ \\
\hline
\end{tabular}




\begin{tabular}{ccc}
\hline & $\begin{array}{c}\text { Cases }(\mathbf{N}=\mathbf{4 0 7}) \\
\mathbf{n}(\boldsymbol{\%})\end{array}$ & $\begin{array}{c}\text { Controls }(\mathbf{N}=\mathbf{2 0 7 5}) \\
\mathbf{n}(\boldsymbol{\%})\end{array}$ \\
\hline 1998 & $77(18.9)$ & $396(19.1)$ \\
1999 & $27(6.6)$ & $135(6.5)$ \\
\hline
\end{tabular}




\section{Table 3}

Crude and Adjusted Odds Ratios (ORadj) and 95\% Confidence Intervals (CIs) for Autism Spectrum Disorders (ASD) Associated with Any Maternal Infection, Kaiser Permanente Northern California Childhood Autism Perinatal Study, 1995 - 1999

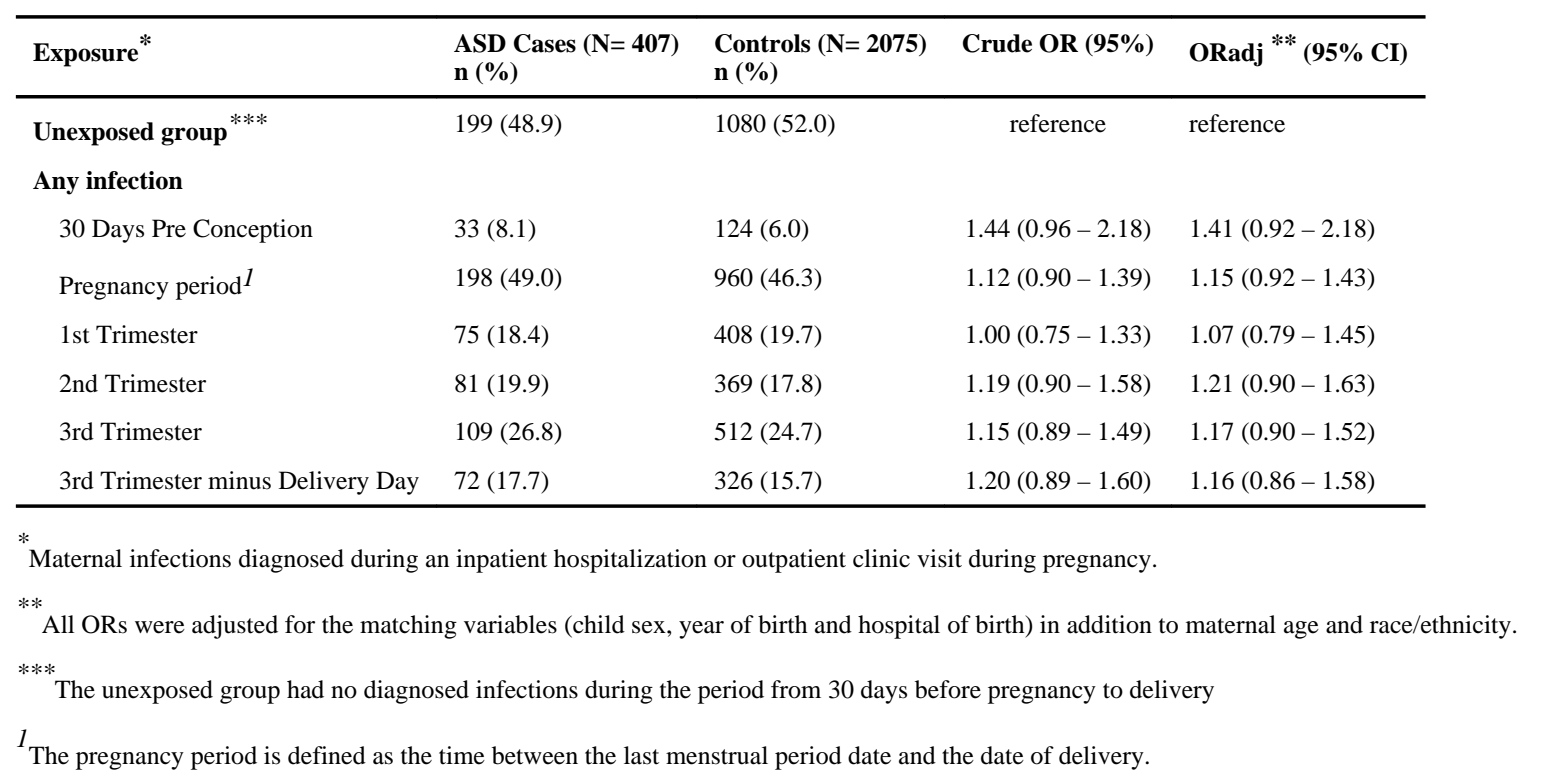




\section{Table 4}

Crude and Adjusted Odds Ratios (ORadj) and 95\% Confidence Intervals (CIs) for Autism Spectrum Disorders (ASD) Associated with Organ Specific Infections, Kaiser Permanente Northern California Childhood Autism Perinatal Study, 1995 - 1999

\begin{tabular}{|c|c|c|c|c|}
\hline Exposure $^{*}$ & $\begin{array}{c}\text { ASD Cases (N=407) } \\
n(\%)\end{array}$ & $\begin{array}{c}\text { Controls }(\mathrm{N}=2075) \\
\text { n }(\%)\end{array}$ & Crude OR (95\% CI) & $\operatorname{ORadj}^{* *}(95 \%$ CI $)$ \\
\hline Unexposed group ${ }^{* * *}$ & 199 (48.9) & $1080(52.0)$ & reference & reference \\
\hline \multicolumn{5}{|l|}{ Genitourinary infection } \\
\hline 30 Days Pre Conception & $6(1.5)$ & $31(1.5)$ & $1.05(0.43-2.55)$ & $1.07(0.42-2.67)$ \\
\hline Pregnancy period ${ }^{l}$ & $73(17.9)$ & $299(14.4)$ & $1.32(0.98-1.78)$ & $1.39(1.02-1.90)$ \\
\hline 1st Trimester & $16(3.9)$ & $94(4.5)$ & $0.92(0.53-1.60)$ & $0.98(0.54-1.77)$ \\
\hline 2nd Trimester & $23(5.6)$ & $83(4.0)$ & $1.50(0.92-2.44)$ & $1.58(0.95-2.63)$ \\
\hline 3rd Trimester & $40(9.8)$ & $156(7.5)$ & $1.39(0.95-2.03)$ & $1.47(0.99-2.17)$ \\
\hline \multicolumn{5}{|l|}{ Lower respiratory infection } \\
\hline 30 Days Pre Conception & $3(0.7)$ & $15(0.7)$ & - & - \\
\hline Pregnancy period $l$ & $35(8.6)$ & $153(7.4)$ & $1.24(0.83-1.85)$ & $1.20(0.80-1.81)$ \\
\hline 1st Trimester & $10(2.5)$ & $45(2.2)$ & $1.21(0.60-2.43)$ & $1.22(0.60-2.51)$ \\
\hline 2nd Trimester & $11(2.7)$ & $55(2.6)$ & $1.08(0.56-2.11)$ & $1.05(0.52-2.08)$ \\
\hline 3rd Trimester & $14(3.4)$ & $68(3.3)$ & $1.12(0.62-2.02)$ & $1.01(0.54-1.87)$ \\
\hline \multicolumn{5}{|l|}{ Upper respiratory infection } \\
\hline 30 Days Pre Conception & $12(2.9)$ & $58(2.8)$ & $1.12(0.59-2.13)$ & $1.03(0.53-1.99)$ \\
\hline Pregnancy period $l$ & $76(18.7)$ & $386(18.6)$ & $1.07(0.80-1.43)$ & $1.05(0.78-1.42)$ \\
\hline 1st Trimester & $26(6.4)$ & $129(6.2)$ & $1.09(0.70-1.71)$ & $1.09(0.69-1.74)$ \\
\hline 2nd Trimester & $31(7.6)$ & $163(7.8)$ & $1.03(0.68-1.56)$ & $1.00(0.65-1.53)$ \\
\hline 3rd Trimester & $33(8.1)$ & $150(7.2)$ & $1.19(0.79-1.79)$ & $1.15(0.76-1.75)$ \\
\hline \multicolumn{5}{|l|}{ Skin infection } \\
\hline 30 Days Pre Conception & $6(1.5)$ & $11(0.5)$ & $2.96(1.08-8.10)$ & $3.43(1.21-9.70)$ \\
\hline Pregnancy period ${ }^{l}$ & $13(3.2)$ & $91(4.4)$ & $0.77(0.42-1.41)$ & $0.80(0.43-1.47)$ \\
\hline 1st Trimester & $4(1.0)$ & $36(1.7)$ & - & - \\
\hline 2nd Trimester & $6(1.5)$ & $39(1.9)$ & $0.83(0.35-2.0)$ & $0.83(0.34-2.02)$ \\
\hline 3rd Trimester & $7(1.7)$ & $29(1.4)$ & $1.31(0.57-3.03)$ & $1.45(0.60-3.48)$ \\
\hline \multicolumn{5}{|l|}{ Unknown } \\
\hline 30 Days Pre Conception & $2(0.50)$ & $15(0.7)$ & - & - \\
\hline Pregnancy period ${ }^{l}$ & 88 (21.6) & $383(18.5)$ & $1.25(0.94-1.64)$ & $1.36(1.01-1.83)$ \\
\hline 1st Trimester & $32(7.8)$ & $154(7.4)$ & $1.13(0.75-1.70)$ & $1.33(0.83-2.11)$ \\
\hline 2nd Trimester & $20(4.9)$ & $69(3.3)$ & $1.57(0.93-2.65)$ & $1.80(1.04-3.13)$ \\
\hline 3rd Trimester & $43(10.60)$ & $197(9.50)$ & $1.185(0.82-1.70)$ & $1.20(0.82-1.75)$ \\
\hline
\end{tabular}

* Maternal infections diagnosed during an inpatient hospitalization or outpatient clinic visit during pregnancy.

** All ORs were adjusted for the matching variables (child sex, year of birth and hospital of birth) in addition to maternal age and race/ethnicity.

*** The unexposed group had no diagnosed infections during the period from 30 days before pregnancy to delivery.

J Autism Dev Disord. Author manuscript; available in PMC 2016 December 01. 
${ }^{1}$ The pregnancy period is defined as the time between the LMP and the date of delivery. 
Table 5

Crude and Adjusted Odds Ratios (ORadj) and 95\% Confidence Intervals (CIs) for Autism Spectrum Disorders (ASDs) Associated With Selected Organism Specific Infections, Kaiser Permanente Northern California Childhood Autism Perinatal Study, 1995 - 1999

\begin{tabular}{|c|c|c|c|c|}
\hline Exposure $^{*}$ & $\begin{array}{c}\text { ASD Cases }(N=407) \\
n(\%)\end{array}$ & $\begin{array}{c}\text { Controls }(\mathrm{N}=2075) \\
\text { n }(\%)\end{array}$ & Crude OR (95\% CI) & ORadj $^{* * *}(95 \%$ CI $)$ \\
\hline Unexposed group $^{* * *}$ & $199(48.9)$ & $1080(52.0)$ & reference & reference \\
\hline \multicolumn{5}{|l|}{ Bacterial Infection } \\
\hline 30 Days Pre Conception & $6(1.5)$ & $35(1.7)$ & $0.93(0.39-2.24)$ & $0.89(0.36-2.20)$ \\
\hline Pregnancy period ${ }^{l}$ & $67(16.5)$ & $292(14.1)$ & $1.24(0.92-1.69)$ & $1.31(0.96-1.80)$ \\
\hline 1st Trimester & $12(2.9)$ & $69(3.3)$ & $0.94(0.50-1.77)$ & $0.95(0.49-1.84)$ \\
\hline 2nd Trimester & $20(4.9)$ & $61(2.9)$ & $1.78(1.05-3.01)$ & $1.71(0.99-2.96)$ \\
\hline 3rd Trimester & $45(11.1)$ & $186(8.9)$ & $1.31(0.92-1.88)$ & $1.42(0.98-2.06)$ \\
\hline \multicolumn{5}{|l|}{ Viral infection } \\
\hline 30 Days Pre Conception & $2(0.5)$ & $11(0.5)$ & - & - \\
\hline Pregnancy period ${ }^{l}$ & $40(9.8)$ & $184(8.9)$ & $1.18(0.81-1.71)$ & $1.15(0.78-1.68)$ \\
\hline 1st Trimester & $5(1.2)$ & $45(2.2)$ & $0.60(0.24-1.54)$ & $0.63(0.24-1.65)$ \\
\hline 2nd Trimester & $12(2.9)$ & $57(2.7)$ & $1.14(0.60-2.17)$ & $1.06(0.55-2.04)$ \\
\hline 3rd Trimester & $27(6.6)$ & $104(5.0)$ & $1.41(0.90-2.21)$ & $1.35(0.85-2.15)$ \\
\hline \multicolumn{5}{|l|}{ Mycoses Infection } \\
\hline 30 Days Pre Conception & $4(0.9)$ & $10(0.5)$ & - & - \\
\hline Pregnancy period ${ }^{l}$ & $32(7.8)$ & $116(5.6)$ & $1.50(0.98-2.28)$ & $1.53(0.98-2.96)$ \\
\hline 1st Trimester & $9(2.2)$ & $33(1.6)$ & $1.48(0.70-3.14)$ & $1.56(0.71-3.41)$ \\
\hline 2nd Trimester & $11(2.7)$ & $40(1.9)$ & $1.49(0.75-2.96)$ & $1.46(0.71-2.98)$ \\
\hline 3rd Trimester & $14(3.4)$ & $48(2.3)$ & $1.58(0.86-2.92)$ & $1.64(0.87-3.10)$ \\
\hline \multicolumn{5}{|l|}{ Unknown Infection } \\
\hline 30 Days Pre Conception & $22(5.4)$ & $79(3.8)$ & $1.51(0.92-2.48)$ & $1.42(0.84-2.39)$ \\
\hline Pregnancy period $l$ & $142(34.9)$ & $690(33.3)$ & $1.15(0.88-1.41)$ & $1.16(0.91-1.48)$ \\
\hline 1st Trimester & $61(15.0)$ & $312(15.0)$ & $1.06(0.77-1.45)$ & $1.14(0.81-1.58)$ \\
\hline 2nd Trimester & $55(13.5)$ & $259(12.5)$ & $1.15(0.83-1.60)$ & $1.22(0.87-1.72)$ \\
\hline 3rd Trimester & $64(15.7)$ & $290(14.0)$ & $1.20(0.89-1.63)$ & $1.22(0.89-1.68)$ \\
\hline
\end{tabular}




\section{Table 6}

Crude and Adjusted Odds Ratios (ORadj) and 95\% Confidence Intervals (CIs) for Autism Spectrum Disorders (ASDs) Associated with Maternal Infections Diagnosed during an Inpatient Hospitalization, Kaiser Permanente Northern California Childhood Autism Perinatal Study, 1995 - 1999

\begin{tabular}{|c|c|c|c|c|}
\hline Exposure & $\begin{array}{c}\text { ASD Cases }(N=407) \\
n(\%)\end{array}$ & $\begin{array}{c}\text { Controls (N=2075) } \\
\mathrm{n}(\%)\end{array}$ & Crude OR $(95 \%$ CI $)$ & OR adj* $(95 \%$ CI $)$ \\
\hline Unexposed group ${ }^{* *}$ & $199(48.9)$ & $1080(52.0)$ & reference & reference \\
\hline \multicolumn{5}{|l|}{ Any infection } \\
\hline Pregnancy period $l$ & $64(15.7)$ & $249(12.0)$ & $1.39(1.02-1.91)$ & $1.48(1.07-2.04)$ \\
\hline 1st Trimester & $2(0.5)$ & $1(0.0)$ & - & - \\
\hline 2nd Trimester & $6(1.5)$ & $11(0.5)$ & $2.96(1.08-8.10)$ & $3.80(1.31-11.08)$ \\
\hline 3rd Trimester & $59(14.5)$ & $242(11.7)$ & $1.32(0.96-1.83)$ & $1.39(1.0-1.94)$ \\
\hline \multicolumn{5}{|l|}{ Bacterial Infection } \\
\hline Pregnancy period 1 & $38(9.3)$ & $150(7.2)$ & $1.38(0.93-2.03)$ & $1.58(1.06-2.37)$ \\
\hline 1st Trimester & 0 & 1 & - & - \\
\hline 2nd Trimester & $4(0.9)$ & $8(0.4)$ & - & - \\
\hline 3rd Trimester & $35(8.6)$ & $144(6.9)$ & $1.32(0.89-1.97)$ & $1.50(1.00-2.27)$ \\
\hline
\end{tabular}

* All ORs were adjusted for the matching variables (child sex, year of birth and hospital of birth) in addition to maternal age and race/ethnicity.

*** The unexposed group had no diagnosed infections during the period from 30 days before pregnancy to delivery.

${ }^{1}$ The pregnancy period is defined as the time between the LMP and the date of delivery. 